\title{
Biogas production in the methane fermentation of excess sludge oxidized with Fenton's reagent
}

\author{
Iwona Zawieja ${ }^{1, *}$, and Kinga Brzeska ${ }^{1}$ \\ ${ }^{1}$ Czestochowa University of Technology, Faculty of Infrastructure and Environment, \\ ul. Brzeznicka 60a, 42-200 Czestochowa, Poland
}

\begin{abstract}
The advanced oxidation processes (AOPs) play an important role in the degradation of hardly decomposable organic pollutants. AOPs methods rely on the production of highly reactive hydroxyl $\mathrm{OH}^{\cdot}$ radicals. The aim of the conducted research was to intensify biogas production in the methane fermentation process of excess sludge subjected to the process of deep oxidation with Fenton's reagent. In the process of oxidation of sewage sludge with the Fenton reagent, doses of iron ions in the range $0.02-0.14 \mathrm{~g} \mathrm{Fe}^{2+} / \mathrm{g}$ TS (total solids) were used Hydrogen peroxide was measured in the proportions 1: 1-1:10 in relation to the mass of iron ions. The basic substrate of the study was excess sludge. In the case of excess sludge oxidation with the use of Fenton's reagent, the most favorable process conditions were considered to be the dose of iron ions $0.08 \mathrm{~g} \mathrm{Fe}^{2+} / \mathrm{g} \mathrm{d}$.m. and a $\mathrm{Fe}^{2+}: \mathrm{H}_{2} \mathrm{O}_{2}$ ratio of 1:5. As a result of subjecting the excess sludge to disintegration with the Fenton reagent in the above-mentioned dose, with respect to the fermentation process of unprocessed sludge, about two-fold increase in the digestion degree of excess sludge and about $35 \%$ increase of the biogas yield was obtained.
\end{abstract}

\section{Introduction}

Irreversible destruction of protein structure, i.e. denaturation, can be caused by physical or chemical factors, such as ionizing radiation, ultrasound, high content of metal ions, or the presence of peroxides. The strong action of the hydroxyl radical has a decisive influence on the removal of pathogenic organisms. The Fenton reaction improves the degree of sludge mineralization, improves the susceptibility of sewage sludge to dewatering, as well as improving their sedimentation properties. Oxidation of sewage sludge with Fenton reagent also leads to changes in the structure of sediments [1,2]. The course of the oxidation process with the Fenton reagent depends on parameters such as the dose of iron and hydrogen peroxide, the $\mathrm{Fe}^{2+}$ to $\mathrm{H}_{2} \mathrm{O}_{2}$ weight ratio, the presence of reaction catalysts, the reaction of the environment, process temperature and time of the reaction. The concentration and type of the oxidized substance as well as the presence of other impurities also have a significant influence. The efficiency of oxidation of inorganic impurities is greater than that of organic substances, which results from their complicated structure and, consequently, lower susceptibility to oxidation. Oxidation is a multi-stage process, and in

*Corresponding author: izawieja@is.pcz.czest.pl 
the case of organic compounds does not go to completion [3]. The optimal value of the $\mathrm{Fe}^{2+} / \mathrm{H}_{2} \mathrm{O}_{2}$ weight ratio may vary within a wide range from 0.1 to 0.75 . As the concentration of iron (II) ions increases, the efficiency of degradation of pollutants is increased. The boundary value of the $\mathrm{Fe}^{2+} / \mathrm{H}_{2} \mathrm{O}_{2}$ ratio is from 0.5 to 0.75 . Above this value, the addition of iron compounds becomes ineffective [4]. Andrews et al. [5], as a result of subjecting preliminary sludge and waste activated sludge to oxidation with the Fenton reagent, they noticed an improvement in their susceptibility to dehydration as well as a significant reduction in the number of pathogenic microorganisms present in them. They also observed a decrease in the content of copper, zinc, cadmium and nickel in the prepared sludge. Oxidation may result in the reduction of heavy metals by eluting from sludge in an acidic environment to the supernatant. Zhen et al. [6] have noted that the pretreatment of sewage sludge with Fenton's reagent leads to the breakdown of sludge flocs, lysis of microbial cells and the release of organic matter from the inside of the cells. The use of Fenton's reagent results in a significant reduction of pathogenic microorganisms, which makes the sewage sludge sanitary-safe. As an important factor affecting the process of bacterial elimination during oxidation, in addition to the reaction environment, the Fenton reactin is mentioned, as well as the proportions by weight of $\mathrm{FeSO}_{4}$ to $\mathrm{H}_{2} \mathrm{O}_{2}$. According to Wołczyński and others [7], the introduction of a strong chemical oxidant has a stimulating effect on the distribution of the organic fraction of sludge, both readily biodegradable and less susceptible to biological decomposition, which contributes directly to shortening the time of biological stabilization and thus saving energy. The use of Fenton's reagent during the oxidation of sewage sludge has a significant impact on the quality of the supernatant liquid. The studies of Mustranty and others [8] show that during oxidation the susceptibility of organic compounds present in the supernatant liquid to biodegradation is improved. According to Neyens and others [9], with the increase of the concentration of hydrogen peroxide the concentration of dissolved organic substances increase. As Pham et al. reported [10] the increase of the concentration of dissolved organic substances expressed by SCOD increment was obtained using the same doses of Fenton reagent at a lower temperature, i.e. $25^{\circ} \mathrm{C}$ and higher, i.e. $70^{\circ} \mathrm{C}$. Dewil [11] conducted disintegration studies showed that the use of Fenton's reagent increases the value of SCOD measured in the overlying water and, as a consequence, the increase in biogas production during anaerobic stabilization modified by the sewage sludge method tested. Unlike other oxidation methods, the use of Fenton's reagent is a simple process that occurs at ambient temperature without the use of additional energy. The hydroxyl radical reacts chemically with the majority of organic contaminants as well as with many inorganic substances, without producing harmful byproducts. An undoubted advantage of this system is the non-toxicity of the reactants. The use of this method does not require the use of specialized equipment. In addition, reagent components are cheap and non-toxic. The disadvantage is the resulting $\mathrm{Fe}(\mathrm{OH})_{3}$ precipitate, which contains large amounts of adsorbed organic compounds. Therefore, work is undertaken to reduce the amount of $\mathrm{Fe}^{2+}$ ions added during the oxidation with the Fenton reagent and to conduct the process with minimizing the inconvenient sediment of iron (III) hydroxide [12, 13]. An important disadvantage of using the Fenton reagent is also the limited optimal $\mathrm{pH}$ range. The Fenton oxidation process most preferably takes place at a $\mathrm{pH}$ of about 3 [14]. The aim of the conducted research was to intensify biogas production in the methane fermentation process of excess sludge subjected to the process of deep oxidation with Fenton's reagent. 


\section{Research methodology}

\subsection{Characteristics of the substrate}

Excess sludge was subjected to resarch. The sludge was collected from a mechanical and biological sewage treatment plant with a daily capacity of about $90000 \mathrm{~m}^{3}$. In order to initiate the methane fermentation process, excessive sludge was inoculated with fermented sludge. Excess slude was collected from the pipeline supplying the sludge to the mechanical thickener. The digestate sludge was collected from the pipeline transporting the sludge from the separated closed fermentation chambers to separate open fermentation chambers.

In the case of methane fermentation processes, in order to initiate the process, excess sludge was mixed with the digested sludge in a volume ratio of 10 to 1 , respectively. Anaerobic stabilization was subjected to:

- unmodified excess sludge,

- excess sludge disintegrated with Fenton's reagent of iron ion mass $0.08 \mathrm{~g} \mathrm{Fe} / \mathrm{g}$ TS (total solids) and the ratio $\mathrm{Fe}^{2+}: \mathrm{H}_{2} \mathrm{O}_{2}$ 1:5.

\subsection{Technological research}

The research concerned the course of the methane fermentation process carried out in a conventional manner and supported by the Fenton reagent. In the first stage of the research, the most beneficial conditions for the disintegration of excessive sludge by Fenton's reagent were selected. In the next stage methane fermentation of non-modified and disintegrated sludge by Fenton reagent with selected reagent doses.

\subsubsection{Disintegration of excess sludge with Fenton reagent}

The advanced oxidation process with Fenton's reagent was carried out in glass vessels with an active volume of $0.25 \mathrm{~L}$. Excess sludges prior to the oxidation process were acidified with a 2 molar solution of $\mathrm{H}_{2} \mathrm{SO}_{4}$ to $\mathrm{pH} 3$. To the acidified sediments heptahydrate iron II $\mathrm{FeSO}_{4} \cdot 7 \mathrm{H}_{2} \mathrm{O}$ was added and a specific volume of $30 \% \mathrm{H}_{2} \mathrm{O}_{2}$ solution, called Perhydrol, was introduced. Doses of reagents were determined in relation to the dry matter content of sludge. The disintegration process was carried out in the range of iron ions doses of 0.02-0.14 g Fe/g TS (total solids). Hydrogen peroxide was measured in the proportions of $1: 1-1: 10$ in relation to the weight of iron ions. Prepared samples of excess sludge prepared with an appropriate dose of iron ions and hydrogen peroxide were stirred with a magnetic stirrer with a constant mixing speed of $200 \mathrm{rpm}$. The reaction time for oxidation of sewage sludge was 60 minutes. Subsequently, the $\mathrm{pH}$ of the samples was adjusted to the optimal value for the menate fermentation carried out in the subsequent stage of the process. For this purpose, the samples were subjected to alkalisation by adding a 4 molar $\mathrm{NaOH}$ solution.

\subsubsection{Methane fermentation of excess sludge}

Methane fermentation of excess sludge was carried out under static conditions for 28 days in a fermentation chamber with an active volume of $18 \mathrm{~L}$. The sludge was stabilized at a constant temperature of $37^{\circ} \mathrm{C}$, characteristic for conducting the process in mesophilic conditions. Anaerobic stabilization of the sludge was carried out in a digester with heating 
elements, a system ensuring constant mixing speed of the chamber contents, a cylinder with a capacity of $10 \mathrm{~L}$ for measuring the volume of evolved biogas and a leveling bottle with a capacity of $10 \mathrm{~L}$.

\subsubsection{Analyzes carried out during tests}

In the case of the conducted process of disintegration of excessive sludge with the Fenton reagent, analyzes of selected indicator such as SCOD, expressing the degree of liquefaction of organic substances contained in sludge. The course of methane fermentation processes of sludge was controlled based on performed physical and chemical analyzes as well as research on the composition and volume of produced biogas. For the collected samples, the $\mathrm{pH}$ of the sludge was determined using the $\mathrm{pH}$ meter of Elmetron type $\mathrm{CP}-411$ according to the PN-EN 12176 standard, as well as the hydration and total solids (TS), volatile suspended solids (VSS) in the sludge according to PN-75 C-04616/01. In the supernatant liquid obtained as a result of centrifugation, general alkalinity and acidity determinations were carried out according to the PN-91/C-04540/05 standard, volatile fatty acids (VFAs) according to $\mathrm{PN}-75 / \mathrm{C}-04616 / 04$ and ammoniacal nitrogen according to standards PN-73/C-04576/02. The soluble chemical oxygen demand (SCOD) was determined by the dichromate method using the spectrophotometer test from HACH 2I00N IS according to ISO 7027. The determination of Kjeldahl nitrogen was made by titration method according to PN-EN 13342. The effects of stabilization processes were determined on the basis of the digestion degree of sludge according to PN-75/C-04616/07, biogas yield and the quality of obtained biogas, ie the percentage share of methane in the biogas mixture with the using GA 2000 analyzer from Geotechnical Instruments.

\section{Results and discussion}

\subsection{The influence of oxidation of excess sludge with Fenton's reagent on the disintegration process}

As a result of the modification of excess sludge with the Fenton reagent, an increase in the concentration of organic substances in the dissolved form determined on the basis of SCOD value was achieved. The increase in the index followed the increase in the doses of $\mathrm{Fe}^{2+}$ ions and $\mathrm{H}_{2} \mathrm{O}_{2}$ volume. Depending on the volume of excess hydrogen peroxide introduced into the sludge, using the tested doses of iron ions, a different course of oxidation processes of organic substances contained in excess sludge was observed. In the case of examined doses of iron ions for the dose of $\mathrm{Fe}^{2+}$ ions equal to $0.02 \mathrm{~g} \mathrm{Fe} / \mathrm{g} \mathrm{TS}$, the smallest increase in SCOD value was obtained for the remaining doses, while conducting oxidation with doses of iron ions from $0.08 ; 0.10$ and $0.12 \mathrm{~g} \mathrm{Fe}^{2+} / \mathrm{g}$ TS there has been an intense increase in the value of SCOD, already with the introduction of the smallest volume of hydrogen peroxide used, with the ratio of $\mathrm{Fe}^{2+}: \mathrm{H}_{2} \mathrm{O}_{2}$ of $1: 1$. Analyzing the effectiveness of the Fenton reagent on the disintegration process, there was a significant increase in the degree of disintegration in the range of iron ions doses of $0.02-0.08 \mathrm{~g} \mathrm{Fe} / \mathrm{g}$ TS. Using a dose of iron ions of $0.1 \mathrm{~g} \mathrm{Fe} / \mathrm{g}$ TS and $0.12 \mathrm{~g} \mathrm{Fe} / \mathrm{g}$ TS there was no significant increase in SCOD, in terms of iron ions, $0.08 \mathrm{~g} \mathrm{Fe} / \mathrm{g}$ TS. The high proportion of iron in relation to the oxidised substrates could contribute to the formation of so-called "Hydroxyl radical scavengers" and thus reduce the efficiency of the process. It was found that for each of the doses of iron ions selected for the study there was a limit value of the proportion of iron ions to hydrogen peroxide, above which no significant increase in SCOD value was noted (Fig. 1). The 
excess sludge was oxidized with a solution of hydrogen peroxide in the presence of iron ions $\left(\mathrm{Fe}^{2+}\right) . \mathrm{Fe}^{2+}$ doses in the range of $0.02-0.12 \mathrm{~g} \mathrm{Fe} / \mathrm{g}$ TS were used in the tests. Hydrogen peroxide was introduced in proportions from 1: 1 to 1:10 in relation to the specific mass of $\mathrm{Fe}^{2+}$ ions. On the basis of SCOD value changes observed during oxidation process the most favorable $\mathrm{Fe}^{2+}: \mathrm{H}_{2} \mathrm{O}_{2}$ ratio was determined for individual doses of $\mathrm{Fe}^{2+}$, determining the increment of SCOD values of sludges disintegrated in relation to unmodified sludge (Table 2).

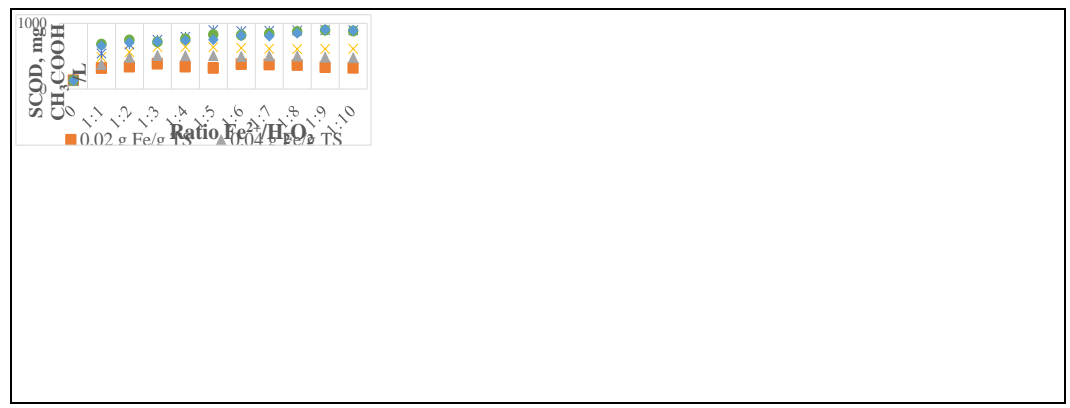

Fig. 1. The effect of the Fenton reagent on the SCOD value depending on the proportion of chemical reagents used.

Table 1. Determination of the most favorable proportions of $\mathrm{Fe}^{2+}: \mathrm{H}_{2} \mathrm{O}_{2}$ for doses of $\mathrm{Fe}^{2+}$ ions based on the increase of the SCOD value of excess sludge modified with Fenton's reagent.

\begin{tabular}{|c|c|c|c|c|c|}
\hline & & $\begin{array}{c}\text { The most } \\
\text { favorable } \\
\text { proportion } \\
\mathrm{Fe}^{2+}: \mathrm{H}_{2} \mathrm{O}_{2}\end{array}$ & $\begin{array}{c}\text { SCOD of } \\
\text { unmodified } \\
\text { sludge, } \\
\text { mg O } / \mathrm{L}\end{array}$ & $\begin{array}{c}\text { SCOD of } \\
\text { oxidized sludge, } \\
\mathrm{mg} \mathrm{O}_{2} / \mathrm{L}\end{array}$ & $\begin{array}{c}\text { Ratio of } \\
\text { SCOD } \\
\text { /SCODmod. }\end{array}$ \\
\hline \multirow{6}{*}{$\begin{array}{c}\text { Dose of } \mathrm{Fe}^{2+}, \\
\text { g Fe/g TS }\end{array}$} & 0.02 & $1: 3$ & 132 & 385 & $1 / 3$ \\
\hline & 0.04 & $1: 3$ & 132 & 510 & $1 / 4$ \\
\hline & 0.06 & $1: 3$ & 132 & 642 & $1 / 5$ \\
\hline & 0.08 & $1: 5$ & 132 & 897 & $1 / 7$ \\
\hline & 0.10 & $1: 9$ & 132 & 895 & $1 / 7$ \\
\hline & 0.12 & $1: 9$ & 132 & 904 & $1 / 7$ \\
\hline
\end{tabular}

\subsection{Methane fermentation of unmodified excess sludge and excess sludge oxidized by Fenton reagent}

Non-processed excess sludge was subjected to methane fermentation. According to literature data $[15,16]$, these sludge are characterized by limited susceptibility to biochemical degradation under anaerobic conditions. The low efficiency of the stabilization process is expressed as a slight production of biogas. The analysis of the values of selected physical and chemical determinations carried out during the process of conventional methane fermentation, as well as the assessment of the effectiveness of the process in terms of biogas production intensity, confirmed the reduced susceptibility of this type of sediment to biochemical degradation under anaerobic conditions. The digestion degree of sludge obtained after 28 days of the process was about $25 \%$. The reduction of the sludge dry mass was $15 \%$. A process of methane fermentation of oxidized excess sludge was carried out. Excess sludge were modified with a dose of iron ions $0.8 \mathrm{~g} \mathrm{Fe} / \mathrm{g} \mathrm{TS}$ and $\mathrm{Fe}^{2+}: \mathrm{H}_{2} \mathrm{O}_{2}$ ratio 1: 5. Doses of specified ragents were considered the most advantageous for the proposed modification. It was assumed that the action of a strong oxidizing reagent would affect the destruction of excess sludge cell microorganisms and release biological material from the 
inside, constituting a kind of substrate for the living heterotrophic mass in stabilization processes. According to the assumption, due to the modification of excess sludge by the proposed method, it is possible to intensify the course of the methane fermentation phases, increase the efficiency of generating volatile fatty acids, and, as a result, increase the production of biogas. As a result of methane fermentation of excess sludge disintegrated with Fenton's reagent at a dose of $0.08 \mathrm{~g} \mathrm{Fe} / \mathrm{g}$ TS and a ratio of $\mathrm{Fe}^{2+}: \mathrm{H}_{2} \mathrm{O}_{2} 1: 5$, a ca. 59\% digestion degree of sludge was recorded. The degree of dry matter reduction was $45 \%$. The results of selected physical and chemical parameters of unmodified excess sludge and excess sludge disintegrated with Fenton's reagent at a dose of $0.08 \mathrm{~g} \mathrm{Fe} / \mathrm{g}$ TS subjected to methane fermentation are presented in Table 2.

Table 2. Changes of physico-chemical parameters of unmodified excess sludge and excess sludge disintegrated by Fenton reagent in the process of methane fermentation.

\begin{tabular}{|c|c|c|c|c|c|}
\hline \multirow{2}{*}{$\begin{array}{c}\text { Indicator/ } \\
\text { Unit }\end{array}$} & \multicolumn{2}{|c|}{$\begin{array}{c}\begin{array}{c}\text { Conventional methane } \\
\text { fermentation of excess } \\
\text { sludge }\end{array} \\
\end{array}$} & \multicolumn{3}{|c|}{$\begin{array}{c}\text { Methane fermentation of excess sludge oxidized with } \\
\text { Fenton reagent at a dose of } 0.8 \mathrm{~g} \mathrm{Fe} / \mathrm{g} \mathrm{TS} \text { and } \\
\qquad \mathrm{Fe}^{2+}: \mathrm{H}_{2} \mathrm{O}_{2} \text { ratio } 1: 5 \\
\end{array}$} \\
\hline & $\begin{array}{l}\text { Excess } \\
\text { sludge }\end{array}$ & $\begin{array}{l}\text { Digested } \\
\text { sludge }\end{array}$ & $\begin{array}{l}\text { Excess } \\
\text { sludge }\end{array}$ & $\begin{array}{l}\text { Disintegrated } \\
\text { excess sludge }\end{array}$ & Digested sludge \\
\hline Hydration, \% & $98.76 \pm 0.01$ & $98.79 \pm 0.01$ & $99.12 \pm 0.002$ & $98.67 \pm 0.02$ & $99.11 \pm 0.014$ \\
\hline TS, g/L & $12.3 \pm 0.1$ & $12.43 \pm 0.12$ & $8.77 \pm 0.02$ & $13.25 \pm 0.19$ & $8.91 \pm 0.14$ \\
\hline VSS, g/L & $8.24 \pm 0.07$ & $6.63 \pm 0.08$ & $6.38 \pm 0.11$ & $6.77 \pm 0.21$ & $3.07 \pm 0.17$ \\
\hline $\begin{array}{l}\text { Acidity, } \\
\text { mval/L }\end{array}$ & $0.8 \pm 0.06$ & $3.4 \pm 0.14$ & $3.2 \pm 0.28$ & $2.2 \pm 0.57$ & $3.6 \pm 0.43$ \\
\hline $\begin{array}{l}\text { Alkalinity, } \\
\text { mval/L }\end{array}$ & $4.4 \pm 0.34$ & $22.6 \pm 0.2$ & $3.6 \pm 0.11$ & $0.4 \pm 0.14$ & $64.8 \pm 2.31$ \\
\hline $\begin{array}{c}\text { SCOD, mg } \\
\mathrm{O}_{2} / \mathrm{L}\end{array}$ & $164 \pm 6.56$ & $428 \pm 5.51$ & $135 \pm 1.41$ & $859 \pm 14.14$ & $492 \pm 12.73$ \\
\hline $\begin{array}{c}\text { VFAs, mg } \\
\mathrm{CH}_{3} \mathrm{COOH} / \mathrm{L} \\
\end{array}$ & $51 \pm 4.85$ & $243 \pm 8.49$ & $60 \pm 14.85$ & $129 \pm 8.57$ & $266 \pm 8.57$ \\
\hline $\begin{array}{c}\text { Kjeldahl } \\
\text { nitrogen, mg } \\
\text { N/L } \\
\end{array}$ & $95 \pm 0.39$ & $403 \pm 1.38$ & $6 \pm 0.4$ & $48 \pm 0.59$ & $358 \pm 1.78$ \\
\hline $\begin{array}{c}\text { Ammonium } \\
\text { nitrogen, mg } \\
\mathrm{N}-\mathrm{NH}^{4+} / \mathrm{L}\end{array}$ & $45 \pm 1.58$ & $344 \pm 0.79$ & $2 \pm 0.4$ & $17 \pm 0.02$ & $353 \pm 1.58$ \\
\hline pH & 7.19 & 7.15 & 7.52 & 6.95 & 7.74 \\
\hline
\end{tabular}

During conventional methane fermentation of excess sludge from 5 to 8 days of the process, a clear increase in biogas production was observed. The highest daily biogas volume of $1.2 \mathrm{~L}$ was recorded in the $7^{\text {th }}$ day of methane fermentation. After the eighth day of the process, the intensity of biogas production decreased. Based on the performed biogas production daily analysis, a total biogas volume of $14.5 \mathrm{~L}$ was obtained. The biogas yield was $0.35 \mathrm{~L} / \mathrm{g}$ VSS. On the basis of the measurements carried out regarding the percentage share of individual components of the captured biogas to the 20th day of the methane fermentation, an increase in methane production to the value of $71.4 \%$ was noted. At the same time, along with the increase in the percentage of methane in biogas, a decrease in the carbon dioxide content from the value of $54.3 \%$ obtained in the 2 nd day of stabilization to the value of $32.7 \%$ in the $28^{\text {th }}$ day of the process was noted. In the analyzed biogas up to the $8^{\text {th }}$ day of the process, a trace of oxygen was observed. As a result of anaerobic stabilization of excess sludge disintegrated with a dose of $0.08 \mathrm{~g} \mathrm{Fe} / \mathrm{g}$ TS and the ratio of $\mathrm{Fe}^{2+}: \mathrm{H}_{2} \mathrm{O}_{2}$ 1: 5 
yielded a total biogas production of $40.85 \mathrm{~L}$. The highest daily biogas production of $4.95 \mathrm{~L}$ was obtained on the 8th day of the process, recording a $75.3 \%$ share of methane in biogas. In subsequent days of methane fermentation, a gradual decrease in the intensity of biogas production was noted. The unit production of biogas was $0.53 \mathrm{~L} / \mathrm{g}$ VSS. In the next days of methane fermentation a gradual decrease in the content of carbon dioxide was noted. On the $2^{\text {nd }}$ and $28^{\text {th }}$ day of stabilization, the content of carbon dioxide in the biogas mixture was $56.1 \%$ and $22.3 \%$, respectively. The presence of oxygen in the tested biogas maintained up to 6 days of stabilization. Daily biogas production obtained in the process of anaerobic stabilization of unmodified excess sludge and excess sludge disintegrated with Fenton's reagent at a dose of $0.08 \mathrm{~g} \mathrm{Fe}^{2+} / \mathrm{g}$ TS shown in Figure 2. Percentage of methane and carbon dioxide in the biogas mixture during anaerobic stabilization of unmodified excess sludge and excess sludge disintegrated with Fenton's reagent are shown in Figure 3.

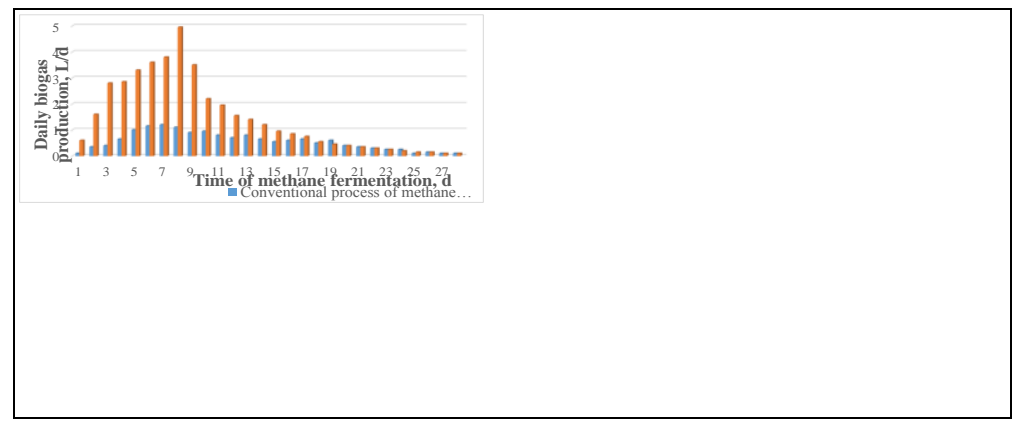

Fig. 2. Daily biogas production in the methane fermentation process.

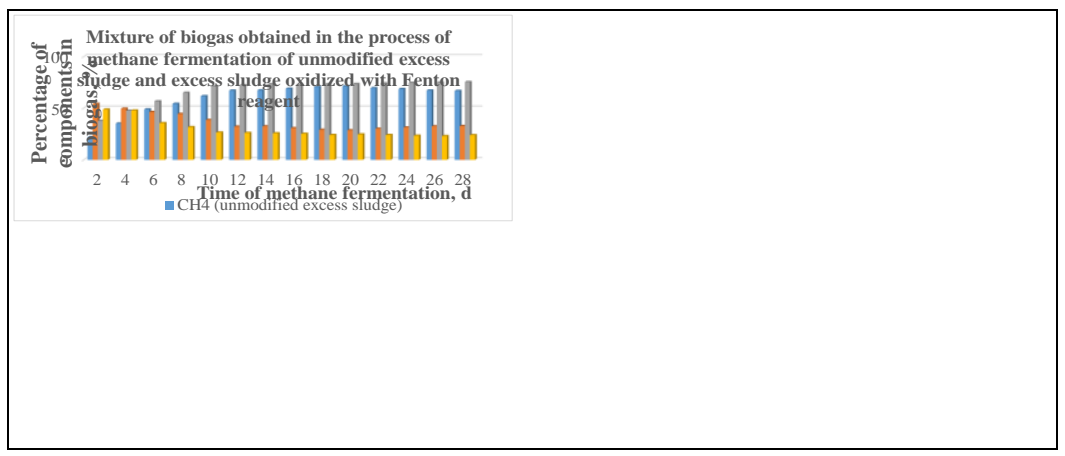

Fig. 3. Changes in the biogas composition in the methane fermentation process.

\section{Conclusions}

The association of the oxidation process with the Fenton reagent using the most advantageous modification conditions with biological hydrolysis contributes to the increase of the digestion degree of sewage sludge and the increment of the biogas yield. The developed technology based on the disintegration process is a promising solution that does not cause secondary pollution of the sludge environment, affecting the methane fermentation process in an effective way. As a result, there is a potential possibility of implementing the proposed technology in the sewage sludge treatment sequence. The analysis of the results obtained in the present study led to the following conclusions: 
1. Subjecting excess sludge to oxidation with Fenton's reagent increased the disintegration of modified sludge, expressed as an increase in the value of soluble chemical oxygen demand (SCOD).

2. As a result of subjecting the sludge to excessive oxidation with the Fenton reagent, an increase in the efficiency of the methane fermentation process, i.e. the digestion degree of sewage sludge and biogas yield, allows the implementation of the developed disintegration concept into the technological sewage sludge treatment process.

3. In the case of oxidation of excess sludge with Fenton reagent the most favorable conditions for the process were considered as the dose of iron ions $0.08 \mathrm{gFe} / \mathrm{g}$ TS and a ratio of $\mathrm{Fe}^{2+}: \mathrm{H}_{2} \mathrm{O}_{2}$ of 1:5. A 7-fold increase in the SCOD value was obtained with respect to the initial values.

4. In the 28-day methane fermentation of excess sludges subjected to oxidation with the Fenton reagent, about $59 \%$ of the digestion degree of excess sludge and the value of biogas yield amounting to $0.53 \mathrm{~L} / \mathrm{g}$ VSS were obtained.

5. As a result of exces sludge subject to advanced oxidation, there was no increase in the methane content in biogas, whose percentage share in the biogas mixture, in the intensive production phase, for the methane fermentation processes carried out, was in the order of $70 \%$.

The research was funded by the project No. BS-PB-401/301/11.

\section{References}

1. R. R. Navarro, H. Ichikawa, K. Tatsumi, Chemosphere 80, 4 (2010)

2. K. Michalska, J. Perkowski, S. Ledakowicz, L. Kos, Chemical Industry 85, 8-9 (2006)

3. S. Ledakowicz, D. Olejnik, J. Perkowski, H. Żegota, Chemical Industry 80, 10 (2001)

4. K. Barbusiński, Advanced oxidation in the treatment of selected industrial wastewater (Publisher of the Silesian University of Technology, Gliwice, 2013)

5. J. Andrews, M. Asaadi, B. Clarke, S.K. Ouki, Y. Zagdaa, J. Residuals, Sci. Tech. 3, 3 (2006)

6. G. Zhen, X. Lu, B. Wang, Y. Zhao, X. Chai, D. Niu, T. Zhao, Front. Env. Sci. Eng. 8, 2 (2014)

7. M. Wołczyński, E. Wiśniowska, M. Janosz-Rajczyk, Environmental Protection Engineering 12, 1 (2009)

8. A. Mustranta, L. Viikari, Water Sci. Technol. 28, 1 (1993)

9. E. Neyens, J. Baeyens, M. Weemaes, B. D. Heyder, Environmental Engineering Science 19, 1 (2002)

10. T. T. Pham, S. K. Brar, R. D. Tyagi, R. Y. Surampalli, J. Environ. Manage. 91, 8 (2010)

11. R. Dewil, L. Appels, J. Baeyens, J. Degrève, J. Hazard. Mater. 146, 3 (2007)

12. K. Michalska, J. Perkowski, S. Ledakowicz, L. Kos, Chemical Industry 85, 8-9 (2006)

13. R. R. Navarro, H. Ichikawa, K. Tatsumi, Chemosphere 80, 4 (2010)

14. S. H. Yuan, N. Gou, A. N. Alshawabkeh, A. Z. Gu, Chemosphere, 93 (2013)

15. J. B. Bień, I. Szparkowska, Environmental Protection Engineering 7, 3-4 (2004)

16. M. Worwąg, A. Grosser, E. Neczaj, T. Kamizela, Annual Set The Environment Protection 20, 512-527 (2018) 